Disponível em

http://www.anpad.org.br/rac

RAC, Rio de Janeiro, v. 18, n. 5, art. 6, pp. 670-694, Set./Out. 2014

http://dx.doi.org/10.1590/1982-7849rac20141865

$($ (c) EY-No

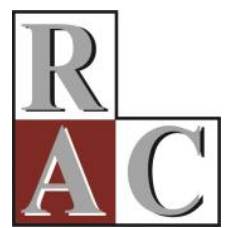

\title{
Estresse, Enfrentamento e Qualidade de Vida: Um Estudo Sobre Gerentes Brasileiros
}

\author{
Stress, Coping Strategies and Quality of Life: A Survey of Brazilian Managers
}

Andre Barcaui

E-mail: barcaui@usp.br

Universidade de São Paulo - FEA/USP

Avenida Professor Luciano Gualberto, 908, sala Butantã, 05508-010, São Paulo, SP, Brasil.

Ana Cristina Limongi-França

E-mail: climongi@usp.br

Universidade de São Paulo - FEA/USP

Avenida Professor Luciano Gualberto, 908, sala Butantã, 05508-010, São Paulo, SP, Brasil.

Artigo recebido em 22.02.2014. Última versão recebida em 03.07.2014. Aprovado em 15.07.2014. 


\title{
Resumo
}

Este estudo analisa a relação entre o estresse percebido no trabalho, a estratégia de enfrentamento adotada e a qualidade de vida de gerentes atuantes em organizações brasileiras. Foram aplicados três instrumentos em conjunto: o Job Stress Scale, de Karasek, o Coping with Job Stress, de Latack, e o WHOQOL - Bref, da OMS, em uma amostra de 1.290 gerentes distribuídos pelo Brasil. Aplicou-se uma análise de correlação entre as variáveis: estresse, qualidade de vida e estratégia de enfrentamento. Para melhor avaliar a relação das três dimensões de interesse, foram desenvolvidos modelos de regressão linear e regressão logística. Os achados demonstraram que a maior parte dos gerentes encontra-se em um nível elevado de estresse, mas com bom suporte social e boa percepção quanto à sua qualidade de vida. A maioria utiliza estratégias de controle para enfrentamento do estresse. As estratégias de controle e administração de sintomas influenciam significativamente a percepção de qualidade de vida, enquanto que estratégias de evitação implicam em diminuição dessa percepção. Gerentes com alta tensão (Karasek \& Theorell, 1990) tendem a ter uma qualidade de vida mais pobre, mesmo moderada pelo apoio social.

Palavras-chave: estresse; estratégia de enfrentamento; qualidade de vida; gerentes.

\begin{abstract}
This study analyzes the relationship between perceived stress at work, the coping strategy adopted, and the quality of life of active managers in Brazilian organizations. Three instruments were applied together: Karasek's Job Stress Scale, Latack's Coping with Job Stress and WHO'S WHOQOL-Bref to a sample of 1290 managers throughout Brazil. An analysis of the correlation between the variables stress, quality of life and coping strategy was applied. To further evaluate the relationship between the three dimensions of interest, linear and logistic regression models were developed. The findings show that most managers find themselves under a high stress level, but share good social support and have good perceptions about their quality of life. Most use control strategies to cope with stress. Control strategies and symptom management significantly influence the perception of quality of life, whereas avoidance strategies imply a decrease in this perception. Managers with jobs classified as high strain (Karasek \& Theorell, 1990) tend to have a poorer quality of life, even when moderated by social support.
\end{abstract}

Key word: stress; coping strategies; quality of life; managers. 


\section{Introdução}

Nas últimas duas décadas, tornou-se crescente o interesse pela relação dinâmica entre estresse, formas de enfrentamento de estresse e qualidade de vida nos mais diversos grupos e segmentos profissionais (Barhem, 2008; Galanakis, Galanopoulou, \& Stalikas, 2011; Ganster, 2005; Hu \& Cheng, 2010; Karthik, 2013; Lu, Kao, Siu, \& Lu, 2010; Parris, Vickerss, \& Wikes, 2008). No Brasil, o interesse pelo tema é contemporâneo e crescente (Barcaui, Vergara, \& Goldszmidt, 2012; Benevides-Pereira, 2002; França, 2007, 2010; Kuchinke, Cornachione, Oh, \& Kang, 2010; Shirrmeister \& França, 2012). Estes estudos destacam características do estresse na organização, sofrimento no trabalho, qualidade de vida no trabalho, impacto organizacional, formas de intervenção, entre outros aspectos. Sobretudo, ao considerar o contexto de pressões sofridas por gerentes em organizações que operam em um país notadamente de contrastes, o qual ao mesmo tempo em que cresce e tenta se estruturar para continuar a ser alvo de investimentos, sofre com diferenças sociais históricas e profundas. Este desafio de modernização aumentou a demanda no ritmo de trabalho, inovação contínua e competição, dessa maneira, influenciando e sendo diretamente influenciado pelo nível de estresse ocupacional de seus executivos (Mukherjee \& Ray, 2009). A especificidade de como cada gestor enfrenta as contingências que a vida corporativa lhe apresenta está na raiz do seu esforço de adaptação ou coping, que pode ser resolvido de várias maneiras, dependendo de cada indivíduo (Carver, Scheier, \& Weintraub, 1989). O impacto desta simbiose entre estresse/coping acaba influenciando também a qualidade de vida percebida por estes profissionais. Sob tal perspectiva e visando contribuir com estudos sobre essa realidade, o presente trabalho teve por objetivo analisar as relações entre estresse no trabalho, estratégias de enfrentamento e qualidade de vida percebida por gerentes em empresas atuantes no Brasil. Para tanto, também, avaliou o nível de qualidade de vida e estresse percebidos por esses profissionais, além de mapear quais formas de enfrentamento de estresse estão sendo adotadas.

O trabalho está estruturado de forma a apresentar, primeiramente, uma revisão bibliográfica relativa ao estresse no trabalho, em particular, o modelo Karasek, estratégias de enfrentamento e qualidade de vida. Depois, são explicitadas as hipóteses levantadas e a metodologia adotada, incluindo o fundamento dos instrumentos utilizados. Por fim, os resultados obtidos são analisados e discutidos à luz da teoria, desse modo, possibilitando e conduzindo a conclusão do artigo.

\section{Estresse no Trabalho}

Uma pesquisa sobre estresse no trabalho, realizada com 984 profissionais nos Estados Unidos, em 2009, pela Associação Americana de Psicologia (American Psychological Association [APA], 2009), aponta que apenas 54\% dos empregados entrevistados recomendariam seu local de trabalho para outras pessoas. A perda de produtividade em função do estresse foi reportada por mais da metade dos participantes no estudo, sendo que a pesquisa do ano anterior apontava para $40 \%$. Se, a esses dados, for acrescentado o fenômeno que, em 2010, o custo anual de presenteísmo foi da ordem de US $\$ 180$ bilhões, suplantando inclusive o custo do absenteísmo propriamente dito, de US\$118 bilhões (Weaver, 2010), infere-se que as organizações e seus gestores não podem mais se dar ao luxo de não aprender a como responder efetivamente aos desafios provocados pelo estresse.

Um estudo feito com 724 gerentes de nível médio, em três diferentes países - Coreia do Sul, Brasil e Estados Unidos - procurou entender o significado do trabalho e analisar sua relação com o estresse (Kuchinke et al., 2010). A conclusão do estudo relata que, enquanto a instituição do trabalho vem mudando ao longo do tempo, o papel exercido pelo trabalho na vida das pessoas não está diminuindo. Para os brasileiros e coreanos, a economia e a orientação ao trabalho estão fortemente associadas a um nível crescente de estresse; já para os americanos, este crescimento estaria ligado a fatores intrínsecos ao próprio contexto de trabalho. Em pesquisa realizada com 353 executivos de empresas de diversos segmentos no Brasil, Barcaui, Vergara e Goldszmidt (2012) verificaram uma correlação positiva entre a percepção do ambiente hostil e o aumento do sofrimento gerencial. Em outro 
estudo realizado na China, quatro indicadores de estresse, em particular, foram direta e positivamente associados à baixa performance. São eles: carga de trabalho, restrições organizacionais, falta de autoridade/autonomia e conflitos interpessoais (Lu et al., 2010).

\section{O modelo Karasek}

Com a proliferação de pesquisas sobre estresse no trabalho, nos últimos anos, cresceu também a quantidade de modelos teórico-metodológicos para avaliar as características desse fenômeno. Entre as teorias propostas, o modelo Demanda-Controle (Karasek, 1979) vem se tornando uma referência, sendo considerado um dos mais utilizados nessas pesquisas (De Lange, Taris, Kompier, Houtman, \& Bongers, 2003, Pelfrene et al., 2001). Segundo Greco, Magnago, Prochnow, Beck e Tavares (2011), na América Latina, até a data de sua pesquisa, foram realizados 35 estudos utilizando o modelo de Karasek, sendo que a maioria desses estudos focou a área de saúde (48.6\%) ou de docência (14.3\%). Mais uma razão que indicava que sua aplicação em outro grupo de profissionais poderia ser reveladora.

O modelo foi introduzido com formato bidimensional relacionando aspectos de demanda e controle no trabalho. Sua idealização sugere que o estresse no trabalho ocorre em função de duas dimensões: as demandas psicológicas percebidas pela pessoa e seu grau de controle sobre suas responsabilidades. As demandas psicológicas podem ser de natureza quantitativa (ex.: tempo para realização de um trabalho) ou qualitativa (ex.: conflitos entre demandas contraditórias). O controle está relacionado ao grau de autonomia, à criatividade e ao poder de decisão que o profissional tem para realização do trabalho que lhe é designado. De acordo com esse modelo inicial, os escores médios são alocados em quatro quadrantes que representam as relações demanda-controle (Figura 1).

\begin{tabular}{|c|c|c|}
$\begin{array}{c}\text { Controle } \\
\text { Baixo } \\
\text { Alto }\end{array}$ & Baixa Pressão & Ativo \\
\hline & & Alta Pressão \\
\hline Passivo & \\
\hline \multicolumn{2}{|c|}{ Baixo Alto } \\
\hline
\end{tabular}

Figura 1. Modelo Demanda-Controle de Karasek.

Fonte: Adaptado de Karasek, R. A., Jr. (1979). Job demand, job decision latitude, and mental strain: implications for job redesign (p. 291). Administrative Science Quarterly, 24(2), 285-308. doi: 10.2307/2392498

Esta proposta gerou basicamente quatro categorias de trabalho: passivo (baixa demanda e baixo controle), ativo (alto controle e alta demanda), de baixo nível de tensão (alto controle e baixa demanda) e alto nível de tensão (baixo controle e alta demanda). São inúmeras as evidências empíricas (De Lange et al., 2003; Häusser, Mojzisch, Niesel, \& Shulz-Hardt, 2010; McClenahan, Giles, \& Mallett, 2007) que corroboram a validade do modelo proposto por Karasek, particularmente nos trabalhos considerados de alto nível de tensão e sua associação ao adoecimento psíquico, estresse, doenças cardíacas e diversas outras patologias. No entanto, apesar da abrangência na aplicação, outra questão que se apresentava é que, além da instância da organização, existe a dimensão individual (valores, crenças, fatores pessoais/contingenciais, entre outros), que não era tratada no modelo. Por esta razão, foi sugerida a ampliação do modelo de Karasek, levando em consideração a avaliação do suporte social (Karasek \& Theorell, 1990), dessa maneira, gerando o modelo Controle-Demanda-Suporte (CDS), que também equaciona a forma que o apoio de colegas e superiores pode mediar/influenciar na relação demanda- 
controle. Ou seja, um modelo ainda mais completo que preconiza que o estresse passaria a ser um produto também de uma dimensão emocional.

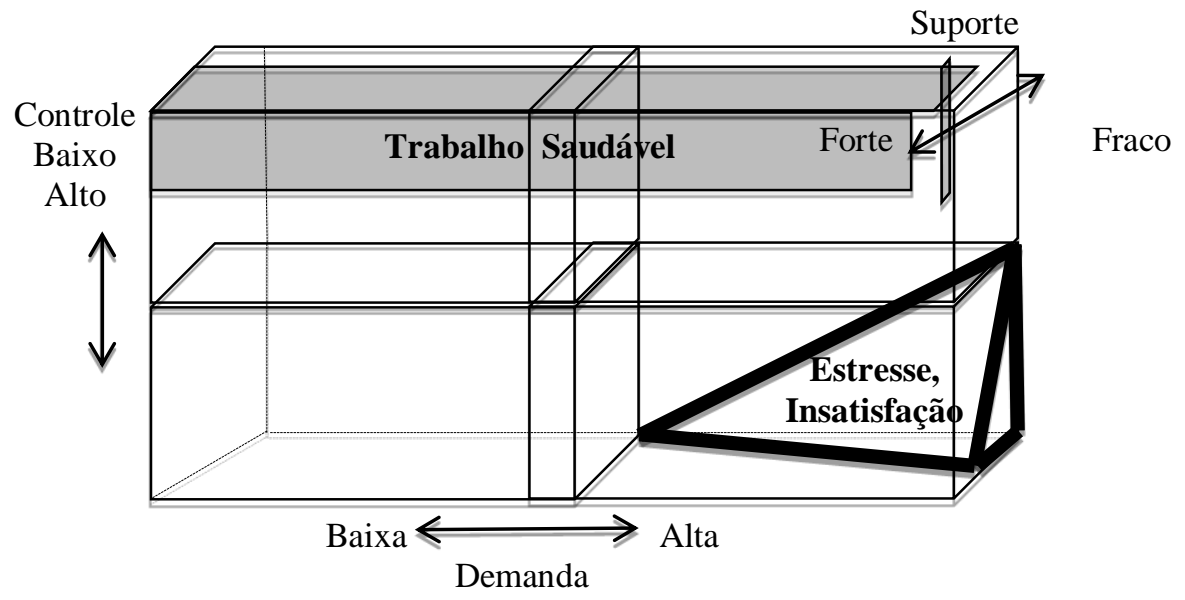

Figura 2. Modelo Controle-Demanda-Suporte de Karasek.

Fonte: Adaptado de Karasek R. A., Jr., \& Theorell, T. (1990). Healthy work: stress, productivity and the reconstruction of working life (pp. 74-78). New York: Basic Books.

Segundo o modelo CDS (Figura 2), profissionais com baixo controle, alta demanda psicológica e baixo nível de suporte tendem a ter mais desgaste, sofrer mais por estresse e insatisfação (Johnson, Hall, \& Theorell, 1989). Da mesma forma, outros estudos sugerem que a influência do suporte social ameniza o impacto de fatores estressores, aumentando a sensação de bem-estar (Choi et al., 2011; Doef, Maes, \& Diekstra, 2000; Griffith, Steptoe, \& Cropley, 1999).

\section{Estratégias de Enfrentamento}

Segundo Giga, Cooper e Faragher (2003), não existe um modelo explanatório sobre o que faz com que as estratégias de enfrentamento (coping) sejam efetivas. Alguns autores seguem uma abordagem de traço de personalidade e outros enfatizam o episódio específico de estresse para analisar a estratégia de enfrentamento. Por isso, existe certa controvérsia em torno do conceito e dos mecanismos de mensuração de coping na literatura (Latack \& Havlovic, 1992), particularmente, no que diz respeito ao seu fraco poder preditivo de comportamento (Dewe, Cox, \& Ferguson, 1993). No entanto, se o coping for considerado como um traço, e, portanto, relativamente estável, as pesquisas quanto às estratégias de enfrentamento seriam pouco práticas em termos de possíveis intervenções e preparação para manejo de situações estressantes (Latack \& Havlovic, 1992).

O chamado coping é caracterizado como um esforço de ação ou pensamento para gerenciar ou sobrepujar situações estressantes (Lazarus \& Folkman, 1984). Latack optou por uma concepção integrativa derivada de uma metanálise de modelos estudados pela autora. As categorias por ela propostas derivam da compilação de outros tratamentos conceituais, tais como os de Folkman (1984), Folkman e Lazarus (1980), Billings e Moos (1984), Carver, Scheier e Weintraub. (1989), Stone e Neale (1984), entre outros. O produto desta revisão de modelos possibilitou a seleção de três novas categorias de estratégias de enfrentamento: (a) controle, incluindo também reavaliações cognitivas feitas pelo indivíduo em relação às situações estressoras (ex.: conversar com colegas que também estejam envolvidos no problema); (b) ações de evitação (ex.: manter distância da situação); e (c) manejo de sintomas, quando se refere a comportamentos visando ao alívio do estresse (ex.: prática de exercícios físicos, relaxamento, ou atividades de lazer).

As três dimensões do modelo de Latack podem ser consideradas como uma evolução em relação à heterogeneidade de modelos, representando um avanço taxonômico nas estratégias de enfrentamento (Pinheiro, Tróccoli, \& Tamayo, 2003). Em outras palavras, a estratégia de enfrentamento pode ser 
entendida de forma transacional entre o indivíduo e o ambiente, no momento em que esse avalia uma situação como estressante.

Latack (1986) também sugere que a estratégia de controle está positivamente relacionada à satisfação com o trabalho, diretamente em oposição à propensão em deixar o emprego e à ansiedade. A evitação e mesmo a estratégia de manejo de sintomas, segundo a autora, induziriam ao aparecimento de sintomas psicossomáticos, o que leva a concluir que a estratégia de controle seria a mais adequada para obtenção de resultados positivos na administração do estresse. Haynes e Love (2004) realizaram um levantamento com 100 gerentes de projetos na área de construção, no qual identificaram que o estilo de coping mais focado no problema tende a ajustar-se melhor em relação àquele engajado na emoção.

\section{Qualidade de Vida}

Paradoxalmente, no âmbito da administração, o grande desafio tem sido o ajuste entre o desenvolvimento da produtividade e da competitividade corporativa com a devida promoção do bemestar de seus profissionais, no que se refere às suas dimensões biológica, psicológica, social e organizacional, com isso, garantindo a manutenção de sua qualidade de vida (França, 2010). O termo QDV é detentor de diversas definições, mas normalmente está associado ao bem-estar dos colaboradores de uma empresa. Seus aspectos incluem: saúde (física e psicológica), segurança, lazer, ergonomia, o próprio ambiente de trabalho, entre outros. Mas ao mesmo tempo em que possui muitas formulações, sua conceituação se torna complexa. De acordo com Keith (2001), o conceito não pode ser definido ao certo por duas razões. Primeiro, porque se trata de uma caracterização universal e multidimensional, ao mesmo tempo objetiva e subjetiva. Segundo, porque não existe um consenso sobre seu significado, dado que diferentes autores tratam a temática segundo o viés de sua própria área e/ou disciplina.

Feita esta ressalva, uma das definições mais bem-aceitas em QVD é da OMS, que a descreve como "a percepção do indivíduo de sua posição na vida, no contexto da cultura e sistema de valores nos quais ele vive e em relação a seus objetivos, expectativas, padrões e preocupações" (Fleck et al., 2000, p. 179).

Segundo Chitakornkijsil (2010), a preocupação com a qualidade de vida na perspectiva do trabalho, vem despertando cada vez mais interesse, não só acadêmico, mas também na prática organizacional visando à melhoria dessas condições. Particularmente, na esfera gerencial, uma pesquisa realizada por Worral e Cooper (2012), com 1.334 gerentes, na Inglaterra, aponta que a satisfação com o emprego tem diminuído, incluindo deterioração da saúde e da sensação de bem-estar. Ganster (2005) sugere que existe uma correspondência positiva entre a baixa qualidade de vida e a má qualidade de decisões tomadas por executivos, incluindo outras habilidades gerenciais específicas, como negociação, solução de problemas e até mesmo comportamento antissocial. Por sua vez, estudos confirmam (Karthik, 2013; Tulasi \& Vijayalakshmi, 2013) que a qualidade de vida, em sua acepção com o trabalho, pode acabar sendo uma estratégia para aumentar o valor de mercado da empresa. Colaborar para sensação de bem-estar aumenta a produtividade do colaborador e promove a atualização do conhecimento, diminuindo o absenteísmo e aumentando o comprometimento afetivo (Shirrmeister \& França, 2012).

\section{Hipóteses}

Com base nos modelos teóricos estudados sobre estresse, coping e qualidade de vida, foram levantadas as seguintes hipóteses, representadas na Figura 3, a seguir: 


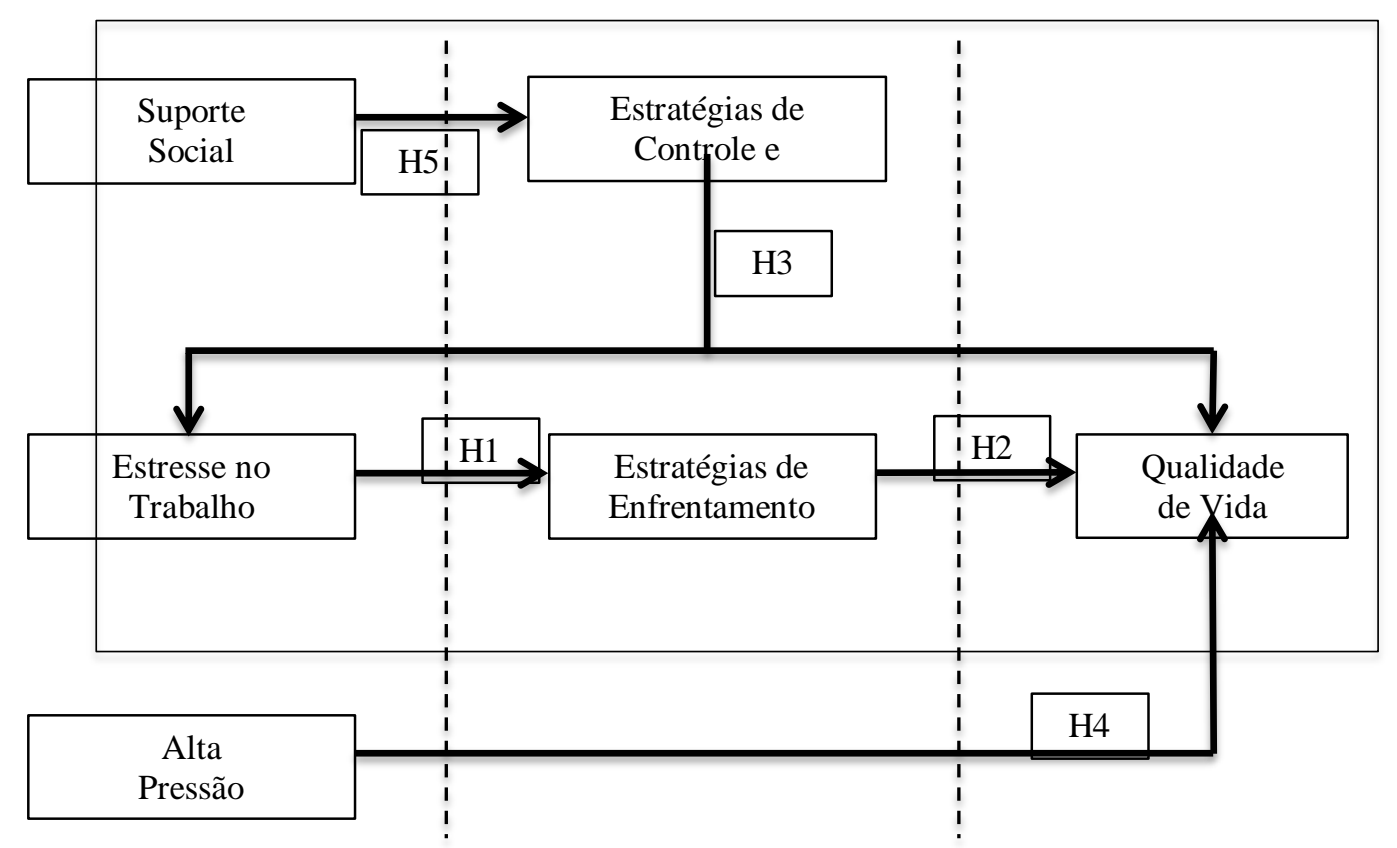

Figura 3. Modelo de Hipóteses ( $\mathrm{H}$ = hipótese).

Hipótese 1 (H1) $\rightarrow$ o estresse no trabalho de gerentes tem influência significante na sua estratégia de enfrentamento.

Hipótese 2 (H2) $\rightarrow$ a estratégia de enfrentamento dos gerentes tem influência significante na sua qualidade de vida.

Hipótese 3 (H3) $\rightarrow$ estratégias de controle e manejo de sintomas moderam a relação do estresse e da qualidade de vida de gerentes.

Hipótese 4 (H4) $\rightarrow$ trabalhos de alta pressão estão positivamente associados à baixa qualidade de vida.

Hipótese 5 (H5) $\rightarrow$ suporte social está positivamente associado a estratégias de controle e manejo de sintomas.

\section{Metodologia}

\section{Participantes}

O público-alvo da pesquisa foi composto por gerentes dos mais diversos níveis hierárquicos, incluindo gerentes de projetos. Ao todo, foram 1.290 respostas coletadas através de um corte transversal entre os meses de agosto e novembro de 2013. Procurou-se deixar claro e ressaltado o caráter voluntário da pesquisa. A maioria dos participantes (Tabela 1) era do sexo masculino (68\%), de 31 a 40 anos (43\%), sendo que $33 \%$ têm entre 1 e 10 funcionários, $24 \%$ têm entre 11 e 50 funcionários e $18 \%$ não têm subordinados. As empresas são em sua maioria do setor privado (80\%), sendo $48 \%$ nacional e $32 \%$ multinacional. 
Tabela 1

Descrição dos Respondentes

\begin{tabular}{|c|c|c|c|}
\hline \multicolumn{3}{|c|}{ Questão } & \multirow{2}{*}{$\frac{\text { Percentual }}{3 \%}$} \\
\hline Idade & Acima de 60 anos & 33 & \\
\hline & Entre 20 e 30 anos & 246 & $19 \%$ \\
\hline & Entre 31 e 40 anos & 551 & $43 \%$ \\
\hline & Entre 41 e 50 anos & 327 & $25 \%$ \\
\hline & Entre 51 e 60 anos & 133 & $10 \%$ \\
\hline & Total geral & 1290 & $100.00 \%$ \\
\hline \multirow[t]{3}{*}{ Gênero } & Feminino & 403 & $31.24 \%$ \\
\hline & Masculino & 887 & $68.76 \%$ \\
\hline & Total geral & 1290 & $100.00 \%$ \\
\hline \multirow{5}{*}{$\begin{array}{l}\text { Âmbito de Atuação da } \\
\text { Organização }\end{array}$} & Privado Multinacional & 413 & $32 \%$ \\
\hline & Privado Nacional & 623 & $48 \%$ \\
\hline & Público & 200 & $16 \%$ \\
\hline & Terceiro Setor & 54 & $4 \%$ \\
\hline & Total geral & 1290 & $100.00 \%$ \\
\hline \multirow{9}{*}{$\begin{array}{l}\text { Quantidade de funcionários } \\
\text { diretos e indiretos que } \\
\text { possui }\end{array}$} & Não tenho funcionários & 232 & $17.98 \%$ \\
\hline & Até 10 funcionários & 427 & $33.10 \%$ \\
\hline & $11-50$ & 305 & $23.64 \%$ \\
\hline & $51-100$ & 97 & $7.52 \%$ \\
\hline & $101-500$ & 84 & $6.51 \%$ \\
\hline & $501-1000$ & 44 & $3.41 \%$ \\
\hline & $1001-5000$ & 42 & $3.26 \%$ \\
\hline & Acima de 5000 & 59 & $4.57 \%$ \\
\hline & Total geral & 1290 & $100.00 \%$ \\
\hline
\end{tabular}

\section{Instrumentos}

Foi elaborado inicialmente um questionário de 85 questões e subdivido em quatro partes: inventário pessoal (13), estresse no trabalho (17), estratégias de enfrentamento (29) e qualidade de vida (26). Este questionário passou por um pré-teste em uma pequena amostra de 50 gerentes escolhidos aleatoriamente entre alunos de pós-graduação deste pesquisador. A partir dos resultados desta aplicação, optou-se pela redução de perguntas de inventário pessoal, totalizando 80 perguntas na versão final. Assim, o inventário pessoal, em seu formato definitivo, ficou com oito perguntas. Não foram observadas quaisquer outras ocorrências que justificassem alterações em outra parte do questionário. Os demais instrumentos escolhidos para medição de estresse no trabalho, estratégias de enfrentamento e qualidade de vida foram: Job Stress Scale (JSS), Coping with Job Stress (CJS) e WHOQOL-Bref, respectivamente. A escolha se deu em função não só da boa aceitação que estes modelos possuem, mas também por sua adaptação já validada para o português do Brasil, uma vez que este pesquisador quis minimizar riscos de interpretações errôneas no seu preenchimento. 
Após o pré-teste, o questionário definitivo foi disponibilizado na internet e enviado por e-mail para diversos contatos gerenciais, aos quais este pesquisador tinha acesso em função de suas atividades como docente e consultor. Sua aplicação também foi incentivada através de visitas a empresas com as quais este pesquisador possuía contato direto no Departamento de Recursos Humanos (ou equivalente). A estratégia adotada foi: uma vez que a área de pessoas tivesse respondido ao questionário, ela própria colaborasse na divulgação a outros gestores da empresa visitada. O tempo de preenchimento do questionário pelos gestores visitados foi de aproximadamente 20 minutos, que se acredita tenha sido o tempo médio para preenchimento de todos os demais respondentes. Em ambos os casos, tanto no envio por e-mail quanto nas visitas, procurou-se deixar claro e ressaltado o caráter voluntário da pesquisa, além da solicitação de divulgação do endereço do questionário para outros profissionais em cargos executivos. Ao todo foram 31 empresas visitadas. Os dados foram analisados utilizando o software livre estatístico $\mathbf{R}$ versão 3.0.2.

\section{Job Stress Scale (JSS) - versão resumida}

Quanto às questões relativas ao estresse, optou-se pela escala Job Stress Scale (JSS) resumida de Karasek, elaborada por Theorell, em 1998 (Alves, Chor, Faerstein, Lopes, \& Werneck, 2004), pela capilaridade que o modelo detém, conforme verificado na revisão teórica e também por já ter sido adaptado e validado para o contexto sociocultural brasileiro, por Alves, Chor, Faerstein, Lopes e Werneck (2004). O instrumento é composto por 17 questões, com valores de 1 a 4, variando de 1 (frequentemente) a 4 (nunca ou quase nunca). A validação brasileira mostrou uma consistência interna que variou entre $0,63<=\alpha<=0,86$. As questões relativas ao estresse no trabalho correspondiam às perguntas 9 a 25 do questionário. A pontuação de cada item é composta pelas medianas dos escores de seus itens para cada gerente. Foram cinco itens representando as demandas psicológicas, seis relativos ao controle e seis relacionados ao suporte.

\section{Coping with Job Stress (CJS)}

Para este estudo, optou-se pela utilização o Escala de Coping Ocupacional de Latack e Havlovic (1992), em função da sua especificidade para a área ocupacional e por já ter sido adaptado e validado para o português do Brasil por Pinheiro, Tróccoli e Tamayo (2003). A escala de Latack é composta por 26 questões, com valores de 1 a 5, segundo a escala Lickert variando de 1 (nunca faço isso) a 5 (sempre faço isso). A validação brasileira mostrou uma consistência interna que variou entre $0,77<=\alpha<=0,81$. As questões relativas à estratégia de enfrentamento de estresse no trabalho correspondiam às perguntas de 26 a 54 do questionário. A pontuação de cada item é composta pela soma de seus itens. $\mathrm{O}$ fator que representa a maior nota é o que foi considerado dominante para cada gerente. Foram 11 questões representando fator controle, nove de evitação e nove relativas ao manejo de sintomas.

\section{WHOQOL - Bref}

Finalmente, para medição da percepção da qualidade de vida dos gerentes, foi utilizado o World Health Organization Quality of Life (WHOQOL) abreviado, da OMS, traduzido e validado para o português por Fleck et al. (2000). O bom desempenho psicométrico e a praticidade são duas das características que fazem desse instrumento um dos mais utilizados para medição da qualidade de vida (Kluthcovsky \& Kluthcovsky, 2006; Saxena, Carlson, Billington, \& Orley, 2001). A validação brasileira revelou uma consistência interna que variou entre $0,66<=\alpha<=0,84$. Esse instrumento consiste de 26 questões com valores variando de 1 a 5 segundo a escala Lickert (perguntas de 55 a 80 do questionário). Os domínios estavam divididos da seguinte forma: aspectos físicos - 11 questões, aspectos psicológicos - seis questões, relações sociais - três questões, e ambiente - oito questões. Existiam ainda mais dois itens sobre a percepção da qualidade de vida em geral do indivíduo. 


\section{Procedimentos}

Esta pesquisa caracteriza-se como um estudo descritivo-correlacional realizado em etapas. Primeiramente, foi desenvolvida uma análise univariada de cada informação coletada nos questionários. Para as perguntas referentes ao estresse, estratégia de enfrentamento e qualidade de vida, foi desenvolvida uma análise descritiva completa, considerando-se a escala Likert com quatro posições para as questões relativas ao estresse e com cinco pontuações para as questões referentes à estratégia de enfrentamento e qualidade de vida, com valores mínimos e máximos, percentis 25, 75 e mediana (percentil 50), média aritmética dos respondentes e desvio padrão. Depois, foi desenvolvida a análise descritiva dos escores (calculada a partir das somas das perguntas relativas a cada segmento do estresse e das médias de cada segmento das perguntas relativas à estratégia de enfrentamento e qualidade de vida) de cada bloco de perguntas (estresse, qualidade de vida e estratégia de enfrentamento); uma análise de distribuição de frequência das caracterizações dos blocos de estresse (alta pressão, baixa pressão, ativo, passivo, alto suporte e baixo suporte, definidas a partir dos valores medianos dos escores de demanda e controle) e estratégia de enfrentamento (controle, administração e evitação). Em seguida, desenvolveu-se uma análise de correlação (Spearman) dos seguintes escores: estresse, qualidade de vida e estratégia de enfrentamento. Para melhor avaliar a relação entre os três blocos de interesse, foram desenvolvidos modelos de regressão linear e regressão logística. O nível de significância considerado foi de 5\% e as suposições dos modelos lineares foram verificadas graficamente.

As variáveis consideradas na modelagem para o bloco estresse foram a caracterização nos quadrantes do modelo Demanda-Controle-Suporte (Karasek \& Theorell, 1990) envolvendo: alta tensão, ativo, baixa tensão e passivo e a caracterização do tipo de suporte recebido, alto ou baixo, ambos definidos a partir das medianas dos escores. Para o bloco de estratégias de enfrentamento, considerouse a estratégia predominante do respondente, que é a maior nota entre controle, administração e evitação. Para os aspectos relativos à percepção de qualidade de vida dos gestores, foi definido um fator geral de qualidade de vida através da análise de componentes principais com todas as variáveis referentes a este bloco, em que a primeira componente gerada foi definida como fator qualidade de vida. Para avaliar a influência do estresse nas estratégias de enfrentamento, foram ajustados três modelos de regressão logística, um para o perfil controle, um para o perfil de administração e um para evitação. Já para avaliar a influência das estratégias de enfrentamento na qualidade de vida, foi ajustado um modelo de regressão linear, cuja variável resposta foi o fator qualidade de vida, que é o resultado da análise de componentes principais. Por fim, para avaliar se as estratégias de enfrentamento positivas (administração e controle) diminuem o impacto do estresse na qualidade de vida, foram ajustados dois modelos de regressão avaliando o impacto do estresse na qualidade de vida: um para o público caracterizado por evitação e outro para o público que optou por administração ou controle.

\section{Análise e Discussão dos Resultados}

Os escores consolidados das perguntas foram analisados da mesma forma (Tabelas 2, 3, 4). No bloco de estresse, detectou-se que os respondentes têm a pontuação mais concentrada em valores mais altos. Verificou-se um reflexo daquilo que a literatura comenta sobre as características do trabalho gerencial, envolvendo: dinamismo, pressão por resultados, necessidade constante de treinamento, entre outras (Mukherjee \& Ray, 2009; Parris et al., 2008; Worral \& Cooper, 2012). A estratégia de enfrentamento predominante foi de controle, seguida pela administração dos sintomas, indicando que a maioria dos gerentes brasileiros adota estratégias de enfrentamento proativas, o que é compatível com o resultado da pesquisa de Haynes e Love (2004), conforme o paradigma de Latack (1986). 
Tabela 2

Análise Univariada das Perguntas Relativas ao Estresse

\begin{tabular}{|c|c|c|c|c|c|c|c|}
\hline Pergunta & Mín. & Pct 25 & Média & Mediana & Pct 75 & Máx. & $\begin{array}{l}\text { Desvio } \\
\text { padrão }\end{array}$ \\
\hline $\begin{array}{l}\text { Com que frequência você tem que fazer } \\
\text { suas tarefas de trabalho com muita } \\
\text { rapidez? }\end{array}$ & 1 & 3 & 3.64 & 4 & 4 & 4 & 0.53 \\
\hline $\begin{array}{l}\text { Com que frequência você tem que } \\
\text { trabalhar intensamente (isto é, produzir } \\
\text { muito em pouco tempo)? }\end{array}$ & 1 & 3 & 3.57 & 4 & 4 & 4 & 0.57 \\
\hline Seu trabalho exige demais de você? & 1 & 3 & 3.44 & 3 & 4 & 4 & 0.60 \\
\hline $\begin{array}{l}\text { Você tem tempo suficiente para } \\
\text { cumprir todas as tarefas de } \\
\text { trabalho? }\end{array}$ & 1 & 1 & 2.05 & 2 & 3 & 4 & 0.82 \\
\hline $\begin{array}{l}\text { O seu trabalho costuma apresentar } \\
\text { exigências contraditórias } \\
\text { discordantes? }\end{array}$ & 1 & 3 & 3.11 & 3 & 4 & 4 & 0.75 \\
\hline $\begin{array}{l}\text { Você tem possibilidade de aprender } \\
\text { coisas novas em seu trabalho? }\end{array}$ & 1 & 3 & 3.39 & 4 & 4 & 4 & 0.74 \\
\hline $\begin{array}{l}\text { Seu trabalho exige muita habilidade ou } \\
\text { conhecimentos especializados? }\end{array}$ & 1 & 3 & 3.61 & 4 & 4 & 4 & 0.58 \\
\hline $\begin{array}{l}\text { Seu trabalho exige que você tome } \\
\text { iniciativas? }\end{array}$ & 1 & 4 & 3.85 & 4 & 4 & 4 & 0.40 \\
\hline $\begin{array}{l}\text { No seu trabalho, você tem que repetir } \\
\text { muitas vezes as mesmas tarefas? }\end{array}$ & 1 & 1 & 1.80 & 2 & 2 & 4 & 0.73 \\
\hline $\begin{array}{l}\text { Você pode escolher COMO fazer o seu } \\
\text { trabalho? }\end{array}$ & 1 & 3 & 3.26 & 3 & 4 & 4 & 0.70 \\
\hline $\begin{array}{l}\text { Você pode escolher O QUE fazer no } \\
\text { seu trabalho? }\end{array}$ & 1 & 2 & 2.72 & 3 & 3 & 4 & 0.81 \\
\hline $\begin{array}{l}\text { Existe um ambiente calmo e agradável } \\
\text { onde trabalho. }\end{array}$ & 1 & 2 & 2.70 & 3 & 3 & 4 & 0.83 \\
\hline $\begin{array}{l}\text { No trabalho, nos relacionamos bem uns } \\
\text { com os outros. }\end{array}$ & 1 & 3 & 3.10 & 3 & 4 & 4 & 0.65 \\
\hline $\begin{array}{l}\text { Eu posso contar com apoio dos meus } \\
\text { colegas de trabalho. }\end{array}$ & 1 & 3 & 3.04 & 3 & 3 & 4 & 0.66 \\
\hline $\begin{array}{l}\text { Se eu não estiver num bom dia, meus } \\
\text { colegas compreendem. }\end{array}$ & 1 & 2 & 2.84 & 3 & 3 & 4 & 0.79 \\
\hline $\begin{array}{l}\text { No trabalho, eu me relaciono bem com } \\
\text { meus chefes. }\end{array}$ & 1 & 3 & 3.27 & 3 & 4 & 4 & 0.71 \\
\hline $\begin{array}{l}\text { Eu gosto de trabalhar com meus } \\
\text { colegas. }\end{array}$ & 1 & 3 & 3.32 & 3 & 4 & 4 & 0.65 \\
\hline
\end{tabular}


Tabela 3

Análise Univariada das Perguntas Relativas às Estratégias de Enfrentamento

\begin{tabular}{|c|c|c|c|c|c|c|c|}
\hline Pergunta & Mín. & Pct 25 & Média & Mediana & Pct 75 & Máx. & $\begin{array}{l}\text { Desvio } \\
\text { padrão }\end{array}$ \\
\hline $\begin{array}{l}\text { Converso com colegas que também } \\
\text { estejam envolvidos no problema. }\end{array}$ & 1 & 3 & 3.89 & 4 & 4 & 5 & 0.81 \\
\hline $\begin{array}{l}\text { Tento ver a situação como uma } \\
\text { oportunidade para aprender } \\
\text { desenvolver novas habilidades. }\end{array}$ & 1 & 3 & 3.87 & 4 & 4 & 5 & 0.80 \\
\hline Dou atenção extra ao planejamento. & 1 & 3 & 3.76 & 4 & 4 & 5 & 0.90 \\
\hline $\begin{array}{l}\text { Penso em mim como alguém que } \\
\text { sempre consegue se sair bem em } \\
\text { situações como esta. }\end{array}$ & 1 & 3 & 3.64 & 4 & 4 & 5 & 0.83 \\
\hline Penso na situação como um desafio. & 1 & 3 & 3.87 & 4 & 4 & 5 & 0.85 \\
\hline $\begin{array}{l}\text { Tento trabalhar mais rápida } \mathrm{e} \\
\text { eficientemente. }\end{array}$ & 1 & 4 & 3.95 & 4 & 4 & 5 & 0.76 \\
\hline $\begin{array}{l}\text { Decido sobre o que deveria ser feito e } \\
\text { comunico às demais pessoas } \\
\text { envolvidas. }\end{array}$ & 1 & 3 & 3.76 & 4 & 4 & 5 & 0.85 \\
\hline $\begin{array}{l}\text { Esforço-me para fazer o que eu acho } \\
\text { que se espera de mim. }\end{array}$ & 1 & 4 & 4.31 & 4 & 5 & 5 & 0.71 \\
\hline $\begin{array}{l}\text { Peço conselhos a pessoas que, embora } \\
\text { estejam fora da situação, possam me } \\
\text { ajudar a pensar sobre o que fazer. }\end{array}$ & 1 & 3 & 3.58 & 4 & 4 & 5 & 0.92 \\
\hline $\begin{array}{l}\text { Tento modificar os fatores que } \\
\text { causaram a situação. }\end{array}$ & 1 & 3 & 3.56 & 4 & 4 & 5 & 0.84 \\
\hline $\begin{array}{l}\text { Envolvo-me mais ainda nas minhas } \\
\text { tarefas, se acho que isso pode ajudar a } \\
\text { resolver a questão. }\end{array}$ & 1 & 4 & 4.04 & 4 & 5 & 5 & 0.79 \\
\hline Evito a situação, se possível. & 1 & 2 & 2.55 & 2 & 3 & 5 & 1.05 \\
\hline $\begin{array}{l}\text { Digo a mim mesmo que o tempo } \\
\text { resolve problemas desta natureza. }\end{array}$ & 1 & 1 & 2.08 & 2 & 3 & 5 & 0.93 \\
\hline Tento manter distância da situação. & 1 & 1 & 1.95 & 2 & 2 & 5 & 0.85 \\
\hline $\begin{array}{l}\text { Procuro lembrar que o trabalho não é } \\
\text { tudo na vida. }\end{array}$ & 1 & 2 & 2.98 & 3 & 4 & 5 & 1.09 \\
\hline $\begin{array}{l}\text { Antecipo as consequências negativas, } \\
\text { preparando-me assim para o pior. }\end{array}$ & 1 & 3 & 3.22 & 3 & 4 & 5 & 0.98 \\
\hline Delego minhas tarefas a outras pessoas. & 1 & 2 & 2.54 & 3 & 3 & 5 & 0.99 \\
\hline $\begin{array}{l}\text { Mantenho a maior distância possível } \\
\text { das pessoas que causaram a situação. }\end{array}$ & 1 & 2 & 2.46 & 2 & 3 & 5 & 0.94 \\
\hline $\begin{array}{l}\text { Tento não me preocupar com a } \\
\text { situação. }\end{array}$ & 1 & 2 & 2.24 & 2 & 3 & 5 & 0.94 \\
\hline $\begin{array}{l}\text { Concentro-me em fazer } \\
\text { prioritariamente aquilo que gosto. }\end{array}$ & 1 & 2 & 2.87 & 3 & 3 & 5 & 0.94 \\
\hline
\end{tabular}


Tabela 3 (continuação)

\begin{tabular}{|c|c|c|c|c|c|c|c|}
\hline Pergunta & Mín. & Pet 25 & Média & Mediana & Pct 75 & Máx. & $\begin{array}{l}\text { Desvio } \\
\text { padrão }\end{array}$ \\
\hline Pratico mais exercícios físicos. & 1 & 2 & 2.61 & 2 & 4 & 5 & 1.26 \\
\hline $\begin{array}{l}\text { Uso algum tipo de técnica de } \\
\text { relaxamento. }\end{array}$ & 1 & 1 & 2.14 & 2 & 3 & 5 & 1.13 \\
\hline Procuro a companhia de outras pessoas. & 1 & 3 & 3.21 & 3 & 4 & 5 & 1.00 \\
\hline Mudo meus hábitos alimentares. & 1 & 2 & 2.55 & 3 & 3 & 5 & 1.12 \\
\hline $\begin{array}{l}\text { Procuro me envolver em mais } \\
\text { atividades de lazer. }\end{array}$ & 1 & 2 & 2.93 & 3 & 4 & 5 & 1.07 \\
\hline Compro alguma coisa. & 1 & 2 & 2.47 & 2 & 3 & 5 & 1.05 \\
\hline Tiro alguns dias para descansar. & 1 & 1 & 2.11 & 2 & 3 & 5 & 0.91 \\
\hline Faço uma viagem. & 1 & 2 & 2.25 & 2 & 3 & 5 & 0.97 \\
\hline Torno-me mais sonhador(a). & 1 & 2 & 2.64 & 3 & 3 & 5 & 1.20 \\
\hline
\end{tabular}

Tabela 4

Análise Univariada das Perguntas Relativas à Qualidade de Vida

\begin{tabular}{|c|c|c|c|c|c|c|c|}
\hline Pergunta & Mín. & Pct 25 & Média & Mediana & Pct 75 & Máx. & $\begin{array}{l}\text { Desvio } \\
\text { padrão }\end{array}$ \\
\hline $\begin{array}{l}\text { Como você avaliaria sua qualidade de } \\
\text { vida? }\end{array}$ & 1 & 3 & 3.50 & 4 & 4 & 5 & 0.90 \\
\hline $\begin{array}{l}\text { Quão satisfeito(a) você está com a sua } \\
\text { saúde? }\end{array}$ & 1 & 2 & 3.25 & 3 & 4 & 5 & 1.02 \\
\hline $\begin{array}{l}\text { Em que medida você acha que sua dor } \\
\text { (física) impede você de fazer o que } \\
\text { precisa? }\end{array}$ & 1 & 3 & 3.94 & 4 & 5 & 5 & 0.97 \\
\hline $\begin{array}{l}\text { O quanto você precisa de algum } \\
\text { tratamento médico para levar sua vida } \\
\text { diária? }\end{array}$ & 1 & 3 & 4.03 & 4 & 5 & 5 & 0.98 \\
\hline O quanto você aproveita a vida? & 1 & 3 & 3.22 & 3 & 4 & 5 & 0.82 \\
\hline $\begin{array}{l}\text { Em que medida você acha que a sua vida } \\
\text { faz sentido? }\end{array}$ & 1 & 4 & 3.96 & 4 & 5 & 5 & 0.85 \\
\hline O quanto você consegue se concentrar? & 1 & 3 & 3.54 & 4 & 4 & 5 & 0.78 \\
\hline $\begin{array}{l}\text { Quão seguro(a) você se sente em sua } \\
\text { vida diária? }\end{array}$ & 1 & 3 & 3.43 & 4 & 4 & 5 & 0.85 \\
\hline $\begin{array}{l}\text { Quão saudável é o seu ambiente físico } \\
\text { (clima, barulho, poluição, atrativos)? }\end{array}$ & 1 & 3 & 3.32 & 3 & 4 & 5 & 0.84 \\
\hline $\begin{array}{l}\text { Você tem energia suficiente para seu dia } \\
\text { a dia? }\end{array}$ & 1 & 3 & 3.42 & 3 & 4 & 5 & 0.83 \\
\hline $\begin{array}{l}\text { Você é capaz de aceitar sua aparência } \\
\text { física? }\end{array}$ & 1 & 3 & 3.75 & 4 & 5 & 5 & 0.99 \\
\hline
\end{tabular}




\section{Tabela 4 (continuação)}

\begin{tabular}{|c|c|c|c|c|c|c|c|}
\hline Pergunta & Mín. & Pct 25 & Média & Mediana & Pct 75 & Máx. & $\begin{array}{l}\text { Desvio } \\
\text { padrão }\end{array}$ \\
\hline $\begin{array}{l}\text { Você tem dinheiro suficiente para } \\
\text { satisfazer suas necessidades? }\end{array}$ & 1 & 3 & 3.21 & 3 & 4 & 5 & 0.90 \\
\hline $\begin{array}{l}\text { Quão disponíveis para você estão as } \\
\text { informações que precisa no seu dia a dia? }\end{array}$ & 1 & 3 & 3.40 & 3 & 4 & 5 & 0.79 \\
\hline $\begin{array}{l}\text { Em que medida você tem oportunidades } \\
\text { de atividade de lazer? }\end{array}$ & 1 & 2 & 3.03 & 3 & 4 & 5 & 0.84 \\
\hline Quão bem você é capaz de se locomover? & 1 & 4 & 4.32 & 5 & 5 & 5 & 0.84 \\
\hline $\begin{array}{l}\text { Quão satisfeito(a) você está com o seu } \\
\text { sono? }\end{array}$ & 1 & 2 & 3.20 & 3 & 4 & 5 & 1.08 \\
\hline $\begin{array}{l}\text { Quão satisfeito(a) você está com sua } \\
\text { capacidade de desempenhar as atividades } \\
\text { do seu dia a dia? }\end{array}$ & 1 & 3 & 3.49 & 4 & 4 & 5 & 0.92 \\
\hline $\begin{array}{l}\text { Quão satisfeito(a) você está com sua } \\
\text { capacidade para o trabalho? }\end{array}$ & 1 & 3 & 3.61 & 4 & 4 & 5 & 0.87 \\
\hline $\begin{array}{l}\text { Quão satisfeito(a) você está consigo } \\
\text { mesmo? }\end{array}$ & 1 & 3 & 3.47 & 4 & 4 & 5 & 0.91 \\
\hline $\begin{array}{l}\text { Quão satisfeito(a) você está com suas } \\
\text { relações pessoais (amigos, parentes, } \\
\text { conhecidos, colegas)? }\end{array}$ & 1 & 3 & 3.48 & 4 & 4 & 5 & 0.95 \\
\hline $\begin{array}{l}\text { Quão satisfeito(a) você está com sua vida } \\
\text { sexual? }\end{array}$ & 1 & 2 & 3.26 & 3 & 4 & 5 & 1.10 \\
\hline $\begin{array}{l}\text { Quão satisfeito(a) você está com o apoio } \\
\text { que recebe de seus amigos? }\end{array}$ & 1 & 3 & 3.47 & 4 & 4 & 5 & 0.89 \\
\hline $\begin{array}{l}\text { Quão satisfeito(a) você está com as } \\
\text { condições do local onde mora? }\end{array}$ & 1 & 3 & 3.84 & 4 & 5 & 5 & 1.01 \\
\hline $\begin{array}{l}\text { Quão satisfeito(a) você está com o seu } \\
\text { acesso aos serviços de saúde? }\end{array}$ & 1 & 3 & 3.48 & 4 & 4 & 5 & 1.03 \\
\hline $\begin{array}{l}\text { Quão satisfeito(a) você está com seu } \\
\text { meio de transporte? }\end{array}$ & 1 & 3 & 3.45 & 4 & 4 & 5 & 1.16 \\
\hline $\begin{array}{l}\text { Com que frequência você tem } \\
\text { sentimentos negativos tais como: mau } \\
\text { humor, desespero, ansiedade, depressão? }\end{array}$ & 1 & 3 & 3.56 & 4 & 4 & 5 & 0.92 \\
\hline
\end{tabular}

Os fatores de qualidade de vida apresentaram altas pontuações médias, próximas da pontuação máxima, sendo a qualidade de vida física a que apresentou a maior pontuação média, e a qualidade de vida ambiental, menor pontuação geral. A percepção dos gerentes não é muito negativa quanto à sua qualidade de vida, apresentando valores médios por volta de 3.5 para qualidade de vida e 3.25 para saúde. Apesar do corte transversal, esses dados rivalizam em parte com a pesquisa de Worral e Cooper (2012) sob o ponto de vista da percepção dos gestores sobre sua qualidade de vida.

Da amostra completa, 181 gerentes optaram por não responder justamente a essas questões. Mesmo assim, optou-se por avaliar esses não respondentes e compará-los à população total quanto às características sociodemográficas (Tabela 1), buscando por diferenças que pudessem ser destacadas. Esse público tem mais jovens de 20 a 30 anos (35\% contra 19\% na base completa), mais respondentes com menor quantidade de funcionários ( $57 \%$ deles têm até 10 funcionários, contra $51 \%$ da base original) e com maior concentração em empresas do setor privado nacional (54\% contra $48 \%$ na base original). Apesar da ligeira diferença quanto à distribuição das características sociodemográficas, considerou-se 
que não há motivos para imaginar uma forte influência nos resultados dos testes efetuados, dado que a relação entre as variáveis é supostamente homogênea em toda a amostra.

Para análise relativa ao estresse no trabalho, os respondentes foram classificados segundo os quatro quadrantes de Demanda-Controle-Suporte (Karasek \& Theorell, 1990). As categorias geradas foram alta tensão (alta demanda e baixo controle), ativo (alta demanda e alto controle), baixa tensão (baixa demanda e alto controle) e passivo (baixa demanda e baixo controle). A definição de alto e baixo deu-se a partir dos valores medianos dos escores (Tabelas 5), de forma a garantir maior discriminação entre os respondentes a fim de que se pudesse relacionar esta informação aos demais blocos de interesse. O nível de suporte foi definido da mesma forma. As distribuições populacionais para esses casos mostram que $30 \%$ dos respondentes estão em situação de alta tensão e $28 \%$ em situação ativa, ou seja, $57 \%$ se apresentam em situações de estresse alto/moderado (Tabela 6). A maioria dos respondentes se apresenta em situação de alto suporte social (79\%), o que, segundo a teoria de Karasek, confere certo lastro moderador para trabalhos de alta tensão (Tabela 7).

Tabela 5

Análise Univariada dos Escores dos Diferentes Blocos de Informação

\begin{tabular}{llccccccc}
\hline $\begin{array}{l}\text { Bloco de } \\
\text { informação }\end{array}$ & Escore & Mín. & Pct 25 & Média & Mediana & Pct 75 & Máx. & $\begin{array}{c}\text { Desvio } \\
\text { padrão }\end{array}$ \\
\hline Estress & Demanda psicológica & 7 & 14 & 15.82 & 16 & 17 & 20 & 2.19 \\
& Controle & 8 & 17 & 18.62 & 19 & 20 & 24 & 2.29 \\
& Suporte social & 8 & 16 & 18.27 & 18 & 21 & 24 & 3.18 \\
\multirow{2}{*}{$\begin{array}{l}\text { Estratégias de } \\
\text { enfrentamento }\end{array}$} & Controle & 2.27 & 3.55 & 3.84 & 3.82 & 4.18 & 5 & 0.46 \\
& Evitação & 1.11 & 2.22 & 2.54 & 2.56 & 2.89 & 4.56 & 0.53 \\
\multirow{2}{*}{$\begin{array}{l}\text { Qualidade de de } \\
\text { vida }\end{array}$} & Administração & 1 & 2.11 & 2.55 & 2.56 & 3 & 4.89 & 0.67 \\
& Psica & 1.71 & 3.29 & 3.72 & 3.86 & 4.14 & 5 & 0.63 \\
& Relação & 1.17 & 3.17 & 3.58 & 3.67 & 4 & 5 & 0.62 \\
& Ambiente & 1 & 3 & 3.40 & 3.33 & 4 & 5 & 0.80 \\
Autoavaliação & Qualidade de vida & 1.63 & 3 & 3.39 & 3.38 & 3.75 & 4.88 & 0.56 \\
& Saúde & 1 & 2 & 3.25 & 3 & 4 & 5 & 1.02 \\
\hline
\end{tabular}

Tabela 6

Análise de Perfil dos Respondentes Quanto ao Estresse no Trabalho

\begin{tabular}{lcccc}
\hline Estresse & Frequência & Percentual & $\begin{array}{c}\text { Frequência } \\
\text { acumulada }\end{array}$ & $\begin{array}{c}\text { Percentual } \\
\text { acumulado }\end{array}$ \\
\hline Alta tensão & 377 & 29.22 & 377 & 29.22 \\
Ativo & 361 & 27.98 & 738 & 57.21 \\
Baixa tensão & 311 & 24.11 & 1049 & 81.32 \\
Passivo & 175 & 13.57 & 1224 & 94.88 \\
(vazio) & 66 & 5.12 & 1290 & 100.00 \\
\hline
\end{tabular}


Tabela 7

Análise de Perfil dos Respondentes Quanto ao Suporte Social

\begin{tabular}{lcccc}
\hline Suporte & Frequência & Percentual & $\begin{array}{c}\text { Frequência } \\
\text { acumulada }\end{array}$ & $\begin{array}{c}\text { Percentual } \\
\text { acumulado }\end{array}$ \\
\hline Baixo & 211 & 16.36 & 211 & 16.36 \\
Alto & 1013 & 78.53 & 1224 & 94.88 \\
(vazio) & 66 & 5.12 & 1290 & 100.00 \\
\hline
\end{tabular}

Com relação ao perfil de estratégia de coping, revelou-se que a maioria $(81 \%)$ se caracteriza por usar estratégia predominantemente de controle, seguida por evitação (3\%) e administração (2\%).

Tabela 8

Análise de Perfil dos Respondentes Quanto às Estratégias de Enfrentamento

\begin{tabular}{lcccc}
\hline Estratégia de enfrentamento & Frequência & Percentual & $\begin{array}{c}\text { Frequência } \\
\text { acumulada }\end{array}$ & $\begin{array}{c}\text { Percentual } \\
\text { acumulado }\end{array}$ \\
\hline Administração & 29 & 2.25 & 29 & 2.25 \\
Controle & 1043 & 80.85 & 1072 & 83.10 \\
Evitação & 37 & 2.87 & 1109 & 85.97 \\
(vazio) & 181 & 14.03 & 1290 & 100.00 \\
\hline
\end{tabular}

Os três blocos de variáveis de maior interesse foram relacionados através do cálculo de correlação de Spearman (não supõe linearidade) de seus escores, conforme Tabelas 9, 10 e 11 em que foram destacadas correlações acima de $30 \%$ (positiva ou negativa).

Tabela 9

Correlação de Spearman Entre os Escores de Estresse e Demais Escores

\begin{tabular}{|c|c|c|c|c|c|c|c|c|c|}
\hline & \multicolumn{3}{|c|}{$\begin{array}{c}\text { Estratégia de } \\
\text { enfrentamento }\end{array}$} & \multicolumn{3}{|c|}{ Qualidade de Vida } & \multicolumn{3}{|c|}{ Autoavaliação } \\
\hline & $\begin{array}{l}\frac{0}{0} \\
\text { ठ் }\end{array}$ & 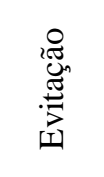 & 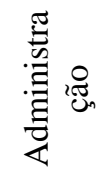 & $\frac{\widetilde{U}}{0}$ & $\begin{array}{l}\frac{\tilde{U}}{0} \\
\frac{0}{0} \\
\frac{0}{0} \\
\frac{0}{n} \\
2\end{array}$ & 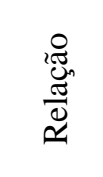 & & 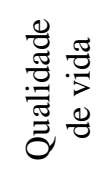 & $\begin{array}{l}\frac{8}{\tilde{n}} \\
\text { : }\end{array}$ \\
\hline Demanda psicológica & -0.09 & -0.02 & -0.19 & -0.31 & -0.31 & -0.23 & -0.30 & -0.36 & -0.24 \\
\hline Controle & 0.21 & -0.05 & 0.14 & 0.29 & 0.34 & 0.20 & 0.37 & 0.27 & 0.17 \\
\hline Suporte social & 0.23 & -0.08 & 0.18 & 0.34 & 0.40 & 0.31 & 0.41 & 0.39 & 0.27 \\
\hline
\end{tabular}

Pôde-se observar que, no geral, há uma baixa correlação entre os escores de estresse e as estratégias de enfrentamento. No entanto eles aparecem ligados às informações de qualidade de vida, conforme apontado nas pesquisas de Shirrmeister e França (2012), Parris, Vickerss and Wikes (2008), Richmond e Skitmore (2006). Quanto maior a demanda psicológica, pior a qualidade de vida, sendo a correlação mais forte com a autoavaliação de qualidade de vida. O controle sobre o trabalho aparece positivamente correlacionado à qualidade de vida psicológica e ambiente. Essa constatação reforça os achados de Haynes e Love (2004) e Aydin (2010). 
O suporte social aparece bastante relacionado a todos os aspectos de qualidade de vida, exceto à autoavaliação em relação à saúde, o que corrobora a concepção de Griffith, Steptoe e Cropley (1999), Doef, Maes e Diekstra (2000), uma vez que aponta que estratégias focadas na resolução do problema exercem um forte efeito no suporte social como mediador entre o estresse e a sensação de bem-estar. Em parte, está de acordo, também, com os estudos de Ahmad e Xavier (2010), assumindo networking como um aspecto do suporte social. As estratégias de controle e administração de sintomas estão positivamente relacionadas à qualidade de vida psicológica, sendo que a estratégia de administração do estresse também está positivamente relacionada à autoavaliação de qualidade de vida e saúde. Essa análise é compatível com os estudos de Hu e Cheng (2010), Haynes e Love (2004) e Chao (2011).

Tabela 10

\section{Correlação de Spearman entre Estratégia de Enfrentamento e Demais Escores}

\begin{tabular}{|c|c|c|c|c|c|c|c|c|c|}
\hline & \multicolumn{3}{|c|}{ Estresse } & \multicolumn{3}{|c|}{ Qualidade de Vida } & \multicolumn{3}{|c|}{ Autoavaliação } \\
\hline & 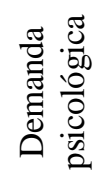 & $\begin{array}{l}\frac{0}{0} \\
\stackrel{0}{0} \\
0 \\
0\end{array}$ & 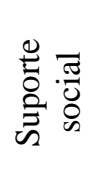 & 谞 & $\begin{array}{l}\frac{\pi}{00} \\
00 \\
0 \\
0 \\
0 \\
0\end{array}$ & 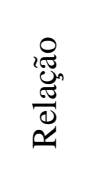 & 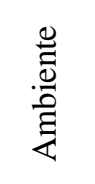 & 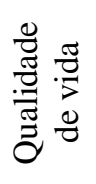 & 莺 \\
\hline Controle & -0.09 & 0.21 & 0.23 & 0.25 & 0.32 & 0.22 & 0.19 & 0.22 & 0.15 \\
\hline Evitação & -0.02 & -0.05 & -0.08 & -0.10 & -0.07 & -0.04 & -0.02 & 0.06 & 0.03 \\
\hline Administração & -0.19 & 0.14 & 0.18 & 0.22 & 0.32 & 0.26 & 0.21 & 0.32 & 0.31 \\
\hline
\end{tabular}

Para avaliar melhor a relação dos três blocos de informação de interesse, foram desenvolvidos modelos de regressão linear e regressão logística (o nível de significância considerado foi de 5\%). As variáveis consideradas para o bloco estresse foram a caracterização no quadrante (alta tensão, ativo, baixa tensão e passivo) e a caracterização de suporte (alto ou baixo). Para o bloco de estratégias de enfrentamento, considerou-se a estratégia predominante do respondente, que é a maior nota entre controle, administração de sintomas e evitação. Por fim, para os aspectos de qualidade de vida, foi criado um fator geral de qualidade de vida que busca explicar todos os aspectos envolvidos e também a autoavaliação em relação à qualidade de vida e saúde, sendo que quanto maior o valor deste fator, melhor a qualidade de vida. O primeiro conjunto de modelos estatísticos ajustados buscou avaliar a influência do estresse nas estratégias de enfrentamento, de forma a testar as hipóteses 1 e 5 deste trabalho. Para tanto, foram ajustados dois modelos de regressão logística em que a variável de interesse (resposta) é uma variável indicadora que pode receber os valores 1 para a ocorrência da categoria e 0 para a não ocorrência.

Os modelos foram desenvolvidos para a estratégia de controle em que a variável de interesse é se o gerente é caracterizado por controle da situação (valor atribuído igual a um) ou não (valor atribuído é igual a zero), outro para a estratégia de administração do estresse em que a variável de interesse é se o gestor é caracterizado por administrar a situação (valor atribuído igual a um) ou não (valor atribuído é igual a zero) e, por fim, um modelo para evitação, em que a variável de interesse é se o gerente é caracterizado por evitação (caso sim, o valor atribuído é 1, caso não, o valor atribuído é 0 ). Vale ressaltar que, como a variável original apresenta três categorias de estratégia predominante de cada gerente, não seria necessário ajustar três modelos, mas somente dois, pois a não ocorrência de duas categorias implica na terceira. No entanto, para facilitar a interpretação, foram observados todos os parâmetros separadamente.

As variáveis explicativas deste modelo foram as categorias do estresse e a qualidade do suporte social (alto ou baixo). As categorias do estresse foram transformadas em quatro variáveis indicadoras de cada categoria, e uma delas foi definida como categoria de comparação, no caso, a variável indicadora de passivo, ou seja, os parâmetros do modelo serão a comparação entre a categoria em questão e a categoria passivo. 
Pôde-se observar que o gerente ativo tem mais chances de apresentar controle em situações de estresse do que o passivo. Alta tensão e baixa tensão não diferem estatisticamente do perfil passivo quanto à chance de ser caracterizado por controle em situações de estresse. Esse achado acrescenta esse dado a outras populações (Greco et al., 2011) que tomaram por base o modelo de Karasek (Karasek \& Theorell, 1990). Evidenciou-se também que o alto suporte social aumenta a chance de o executivo ser controlado em situações de estresse, com isso, ratificando o ponto de vista de Griffith et al. (1999) e Doef et al. (2000).

Tabela 11

Modelo Logístico do Indicador de Controle por Informações Relativas ao Estresse

\begin{tabular}{lccccc}
\hline Variável & Parâmetro & GL & Estimativa & $\begin{array}{c}\text { Qui-quadrado } \\
\text { de Pearson }\end{array}$ & p-valor \\
\hline Intercepto & & 1 & $\mathbf{2 . 1 0 6 8}$ & 69.1128 & $<.0001$ \\
Estresse & Alta tensão & 1 & -0.00105 & 0 & 0.9961 \\
& Ativo & 1 & $\mathbf{0 . 7 5 6 7}$ & 7.5542 & 0.006 \\
& Baixa tensão & 1 & -0.0511 & 0.049 & 0.8249 \\
Suporte & Alto suporte & 1 & $\mathbf{0 . 8 4 7 2}$ & 8.2026 & 0.0042 \\
\hline
\end{tabular}

Nenhuma das variáveis foi significativa com relação ao perfil de administração do estresse. A única variável significativa foi o intercepto (ou média geral) que mostra, com um parâmetro negativo, que a maioria dos executivos não apresenta esse perfil de estratégia de enfrentamento. Essa descoberta vai ao encontro ao trabalho de Barhem (2008) e Richmond e Skitmore (2006), em que pese que sua pesquisa foi concentrada em um público de gerentes de projetos.

Tabela 12

Resultado Modelo Logístico do Indicador de Administração por Informações Relativas ao
Estresse

\begin{tabular}{lccccc}
\hline Variável & Parâmetro & GL & Estimativa & $\begin{array}{c}\text { Qui-quadrado } \\
\text { de Pearson }\end{array}$ & p-valor \\
\hline Intercepto & & 1 & $\mathbf{- 3 . 2 3 1 9}$ & 62.6962 & $<.0001$ \\
Estresse & Alta tensão & 1 & -0.0601 & 0.0347 & 0.8522 \\
& Ativo & 1 & -0.3492 & 0.9869 & 0.3205 \\
& Baixa tensão & 1 & 0.2429 & 0.5981 & 0.4393 \\
Suporte & Alto suporte & 1 & -0.4714 & 1.0228 & 0.3119 \\
\hline
\end{tabular}

Observou-se que o gerente ativo tem menos chances de apresentar evitação em situações de estresse do que o passivo, assim, legitimando a revisão literária estudada (Choi et al., 2011; Hu \& Cheng, 2010). Alta tensão e baixa tensão não diferem estatisticamente do perfil passivo quanto à chance de ser caracterizado por controle em situações de estresse. Individuou-se também que o alto suporte social diminui a chance de o gerente apresentar evitação como característica de enfrentamento em situações de estresse, mais uma vez corroborando a ótica de Griffith et al. (1999) e Doef et al. (2000). 
Tabela 13

Resultado Modelo Logístico do Indicador de Evitação por Informações Relativas ao Estresse

\begin{tabular}{lccccc}
\hline Variável & Parâmetro & GL & Estimativa & $\begin{array}{c}\text { Qui-quadrado } \\
\text { de Pearson }\end{array}$ & p-valor \\
\hline Intercepto & & 1 & $\mathbf{- 2 . 6 8 5 2}$ & 68.6427 & $<.0001$ \\
Estresse & Alta tensão & 1 & 0.1422 & 0.2347 & 0.628 \\
& Ativo & 1 & $\mathbf{- 1 . 1 4 6 3}$ & 6.2804 & 0.0122 \\
& Baixa tensão & 1 & -0.0629 & 0.0338 & 0.8542 \\
Suporte & Alto suporte & 1 & $\mathbf{- 1 . 0 4 8 5}$ & 7.8793 & 0.005 \\
\hline
\end{tabular}

O segundo conjunto de modelos estatísticos ajustados buscou avaliar a influência das estratégias de enfrentamento na qualidade de vida para avaliar a hipótese 2 deste trabalho. Para tanto, foi ajustado um modelo de regressão linear em que a variável resposta é um fator que resume a qualidade de vida do gerente, e as variáveis preditoras são as informações indicadoras de predominância do controle e administração do estresse como estratégia de enfrentamento. Novamente, uma categoria foi omitida de forma que os parâmetros estimados comparassem as categorias presentes no modelo com a categoria de comparação, que foi a estratégia de evitação. Para criar uma variável consolidada da qualidade de vida, executou-se uma análise de componentes principais, utilizando os escores de qualidade de vida física, psicológica, relação social, ambiente e escores de autoavaliação de qualidade de vida e saúde. $O$ fator qualidade de vida foi definido como sendo o primeiro fator na explicação da inter-relação entre as variáveis consideradas. O resultado foi um fator que explica $62 \%$ dessas variáveis. Esse alto percentual de explicação deve-se ao fato de que as variáveis são muito correlacionadas (Tabela 14).

Tabela 14

Correlação entre Escores de Qualidade de Vida e Autoavaliação de Qualidade de Vida e Saúde

\begin{tabular}{lcccccc} 
& Física & Psicológica & Relação & Ambiente & $\begin{array}{c}\text { Autoavaliação } \\
\text { - Qualidade } \\
\text { de vida }\end{array}$ & Saúde \\
\hline Física & $100 \%$ & $70 \%$ & $51 \%$ & $56 \%$ & $55 \%$ & $56 \%$ \\
Psicológica & $70 \%$ & $100 \%$ & $62 \%$ & $60 \%$ & $62 \%$ & $53 \%$ \\
Relação & $51 \%$ & $62 \%$ & $100 \%$ & $49 \%$ & $49 \%$ & $42 \%$ \\
Ambiente & $56 \%$ & $60 \%$ & $49 \%$ & $100 \%$ & $57 \%$ & $41 \%$ \\
$\begin{array}{l}\text { Autoavaliação - } \\
\text { Qualidade de vida }\end{array}$ & $55 \%$ & $62 \%$ & $49 \%$ & $57 \%$ & $100 \%$ & $57 \%$ \\
Autoavaliação - Saúde & $56 \%$ & $53 \%$ & $42 \%$ & $41 \%$ & $57 \%$ & $100 \%$ \\
\hline
\end{tabular}

Todas as variáveis foram positivas na definição da nova variável (Tabela 15), sendo que a qualidade de vida psicológica teve maior peso, seguida por qualidade de vida física e autoavaliação de qualidade de vida. $\mathrm{O}$ fator deve ser interpretado de modo que quanto maior seu valor, melhor a qualidade geral de vida. 
Tabela 15

Pesos das Variáveis na Definição do Fator Qualidade de Vida

\begin{tabular}{lcc}
\cline { 2 - 3 } & \multicolumn{2}{c}{ Fator Qualidade de vida } \\
\cline { 2 - 3 } & Variável & Peso no fator \\
\hline Qualidade de vida & Física & 0.43 \\
& Psicológica & 0.45 \\
& Relação & 0.38 \\
Autoavaliação & Ambiente & 0.40 \\
& Qualidade de vida & 0.42 \\
& Saúde & 0.38 \\
\hline
\end{tabular}

Constatou-se que as estratégias de administração e controle apresentaram parâmetros positivos, indicando que, na presença dessas características, aumenta-se a qualidade de vida, enquanto que, na presença de evitação, diminui-se a qualidade de vida, conforme a proposta original de Latack (1986). Verificou-se também que a estratégia de administração do estresse é mais positiva do que o controle, pois seu parâmetro é maior. O modelo foi validado pela análise gráfica de resíduos, que não revelou grandes distorções de normalidade, homocedasticidade e aleatoriedade.

Tabela 16

Influência das Estratégias de Enfrentamento na Qualidade de Vida Geral do Gerente

\begin{tabular}{lcccc}
\hline Variável & GL & $\begin{array}{c}\text { Estimativa do } \\
\text { parâmetro }\end{array}$ & Estatística T & p-valor \\
\hline Intercepto & 1 & $\mathbf{- 1 . 0 2 9 4 8}$ & -3.03 & 0.0025 \\
Controle & 1 & $\mathbf{1 . 0 3 9 2 2}$ & 3.01 & 0.0027 \\
Administração & 1 & $\mathbf{1 . 8 5 4 8 5}$ & 3.73 & 0.0002 \\
\hline
\end{tabular}

Para avaliar se as estratégias de enfrentamento positivas (administração e controle) moderam o impacto do estresse na qualidade de vida, conforme hipótese 3 deste trabalho, foram ajustados dois modelos de regressão. O primeiro avaliando o impacto do estresse na qualidade de vida, para o público caracterizado por evitação; o segundo para o público caracterizado por administração ou controle. O modelo também foi validado pela análise gráfica de resíduos, que não mostrou grandes distorções de normalidade, homocedasticidade e aleatoriedade. Analisando apenas as variáveis significativas nos dois modelos, detectou-se que houve uma diminuição do impacto da alta tensão e do suporte social na qualidade de vida. 
Tabela 17

Influência do Estresse na QVD para o Perfil Evitação na Estratégia de Enfrentamento

\begin{tabular}{lcccc}
\hline Variável & GL & $\begin{array}{c}\text { Estimativa do } \\
\text { parâmetro }\end{array}$ & Estatística T & p-valor \\
\hline Intercepto & 1 & $\mathbf{- 1 . 3 7}$ & -2.25 & 0.0326 \\
Alta tensão & 1 & $\mathbf{- 1 . 4 9}$ & -2.21 & 0.036 \\
Baixa tensão & 1 & 0.10 & 0.12 & 0.9038 \\
Ativo & 1 & $\mathbf{- 4 . 7 8}$ & -2.71 & 0.0115 \\
Suporte social (alto) & 1 & $\mathbf{1 . 8 1}$ & 2.86 & 0.0081 \\
\hline
\end{tabular}

Tabela 18

Influência do Estresse na QVD para o Perfil Administração ou Controle na Estratégia de Enfrentamento

\begin{tabular}{lcccc}
\hline Variável & GL & $\begin{array}{c}\text { Estimativa do } \\
\text { parâmetro }\end{array}$ & Estatística T & p-valor \\
\hline Intercepto & 1 & $\mathbf{- 0 . 6 8}$ & -3.52 & 0.0004 \\
Alta tensão & 1 & $\mathbf{- 1 . 1 1}$ & -6.37 & $<.0001$ \\
Baixa tensão & 1 & $\mathbf{0 . 5 8}$ & 3.27 & 0.0011 \\
Ativo & 1 & -0.14 & -0.8 & 0.423 \\
Suporte social (alto) & 1 & $\mathbf{1 . 1 3}$ & 7.55 & $<.0001$ \\
\hline
\end{tabular}

A partir dos modelos supraindicados, é possível inferir, também, que a presença de alta tensão diminui a qualidade de vida (hipótese 4) nos dois públicos, pois, em ambos os casos, essa variável aparece significativa a $5 \%$ e negativamente relacionada ao fator geral de qualidade de vida.

\section{Conclusões}

Este estudo teve como objetivo analisar as relações de estresse no trabalho, estratégias de enfrentamento e a qualidade de vida percebida por gerentes em empresas atuantes no Brasil. Sua contribuição se situa na área do comportamento organizacional na medida em que revela novos indícios empíricos sobre o estresse no trabalho gerencial e os impactos causados na vida desses profissionais. Estas evidências podem levar à geração e sustentação de medidas mais efetivas para manuseio do estresse e consequente incremento da qualidade de vida percebida. Pôde-se concluir que a maior parte dos gerentes está com os níveis de estresse elevado, mas com alto suporte social e com boa percepção quanto à qualidade de vida (pontuação acima de 3 ). Com relação às estratégias de enfrentamento, observou-se que a maioria se caracteriza por usar estratégias predominantemente de controle, seguidas por evitação e administração de sintomas.

Não foram detectados altos valores de correlação quanto à análise de correlação relativa à hipótese 1 entre os escores do estresse e de estratégias de enfrentamento. No entanto, após análise de regressão logística, definida a partir da caracterização do gerente, baseada no modelo Karasek (Karasek \& Theorell, 1990) e definição de seu perfil quanto às estratégias de enfrentamento, foi detectada significância estatística, o que vem a fortalecer o uso dessas caracterizações na análise de influências. Ou seja, apesar de não haver o indicativo de relação das pontuações, existe entre as caracterizações dos 
gerentes quanto ao estresse e estratégia de enfrentamento. As estratégias de enfrentamento baseadas na administração de sintomas e no controle influenciam significativamente a qualidade de vida, o que ficou constatado (Tabela 16) a partir deste estudo (hipótese 2). Ao mesmo tempo, as estratégias de evitação sugerem diminuição na percepção de qualidade de vida, corroborando os autores revisados (Haynes \& Love, 2004). Porém a administração dos sintomas se mostrou mais positiva em relação à percepção da qualidade de vida do que ao controle, e isso sugere que mais estudos são necessários para que qualquer ação preditiva possa ser recomendada com mais segurança. Outra caracterização de variável com aspecto positivo foi a definição do fator de qualidade de vida, que trouxe força para as relações de qualidade de vida e estratégia de enfrentamento. Na análise de correlação, apareceram muitas correlações fracas e, inclusive, com dois casos de sinal positivo entre a estratégia de enfrentamento de evitação e qualidade de vida. No entanto, na modelagem, observou-se que a relação dessa estratégia com a qualidade de vida geral é, de fato, negativa.

As hipóteses 3 e 4 deste trabalho estavam relacionadas à moderação entre o estresse e a qualidade de vida através de estratégias de controle e administração de sintomas, e o quanto trabalhos enquadrados na categoria de alta tensão estavam positivamente associados a uma qualidade de vida pobre, respectivamente. A avaliação foi que as estratégias (com exceção da evitação) propiciam uma diminuição do impacto em trabalhos considerados de alta tensão e, consequentemente, melhoram a percepção da qualidade de vida. Além disso, foi possível confirmar que a presença da categoria de alta tensão do modelo de Karasek (Karasek \& Theorell, 1990) implica uma diminuição da percepção de qualidade de vida, independentemente do tipo de estratégia de coping (Tabelas 17 e 18). O suporte social aumenta a chance de o executivo apresentar estratégias positivas (controle e administração de sintomas) em situações de estresse, o que valida a última hipótese deste trabalho.

Outro ponto a ser ressaltado é que a percepção de qualidade de vida dos gerentes está associada à estratégia de enfrentamento, sendo que administrar os sintomas do estresse e adotar estratégias de controle, não só amenizam o impacto do estresse (mesmo em trabalhos de alta tensão), como também aumentam a percepção positiva. Estratégias de evitação têm efeito exatamente oposto na vida dos gerentes.

Em função da própria natureza psicométrica do instrumento, reconhece-se que a amostra representa apenas uma pequena fração do universo de profissionais em cargos gerenciais. Além disso, também aponta apenas para um determinado momento na trajetória profissional do executivo entrevistado, não levando em conta o caráter dinâmico da própria vida. Entende-se também que o questionário e a própria análise quantitativa simbolizam apenas uma parcial da infinidade de possibilidades e combinações de variáveis que podem influenciar tanto o estresse quanto a qualidade de vida percebida pelo gerente. Futuros estudos longitudinais poderão oferecer outra perspectiva na medida em que se possa analisar a evolução dos parâmetros aqui ressaltados na vida do gerente em uma organização.

\section{Referências}

Ahmad, S., \& Xavier, S. (2010). Stress and coping styles of entrepreneurs: a malaysian survey. International Journal of Entrepreneurship, 14(1), 25-35.

Alves, M. G. M. de, Chor, D., Faerstein, E., Lopes, C. S. de, \& Werneck, G. L. (2004). Versão resumida do Job Stress Scale: adaptação para o português. Revista de Saúde Pública, 38(2), 164-171. doi: 10.1590/S0034-89102004000200003

American Psychological Association. (2009). Stress in America. Washington: Author.

Aydin, K (2010). Strategies for coping with stress as predictors of mental health. International Journal of Human Sciences, 7(1), 534-548. 
Barcaui, A., Vergara. S., \& Goldszmidt, R. (2012, junho). The work context as an etiological source of suffering for Brazilian executives. Anais do Congresso de Excelência em Gestão, Rio de Janeiro, RJ, Brasil, $8 . \quad$ Recuperado de http://www.excelenciaemgestao.org/Portals/2/documents/cneg8/anais/T12_0490_2236.pdf

Barhem, B. (2008). Are global managers able to deal with work stress. Journal of Accounting Business \& Management 15(1), 53-70.

Benevides-Pereira, A. (2002). Bornout - quando o trabalho ameaça o bem-estar do trabalhador. São Paulo: Casa do Psicólogo.

Billings, A. G., \& Moos, R. H. (1984). Coping, stress and social resources among adults with unipolar depression. Journal of Personality and Social Psychology, 46(4), 877-891. doi: 10.1037/00223514.46.4.877

Carver, C. S., Scheier, M. F., \& Weintraub, J. K. (1989). Assessing coping strategies: a theoretically based approach. Journal of Personality and Social Psychology, 56(2), 267-283. doi: 10.1037/0022-3514.56.2.26710.1037/0022-3514.56.2.267

Chitakornkijsil, P. (2010). Broad perspective and framework of quality of work life. International Journal of Organization Innovation, 3(2), 214-242.

De Lange, A. H., Taris, T. W., Kompier, M. A. J., Houtman, I. L. D., \& Bongers, P. M. (2003). The very best of the millennium: longitudinal research and the demand-control-(support) model. Journal of Occupational Health Psychology, 8(4), 282-305. doi: 10.1037/1076-8998.8.4.282

Chao, R. C.-L. (2011). Managing stress and maintaining well-being: social support, problem-focused coping, and avoidant coping. Journal of Counseling \& Development, 89(3), 338-348. doi: $10.1002 / \mathrm{j} .1556-6678.2011 . t b 00098 . x$

Choi B., Ostergren, P., Canivet, C., Mohgahdassi, M., Lindeberg, S., Karasek, R., \& Isacsson, S. (2011). Synergetic interaction effect between job control and social support at work on general psychological distress. International Archives of Occupational and Environmental Health, 84(1), 77-89. doi: 10.1007/s00420-010-0554-y

Dewe, P., Cox, T., \& Ferguson, E. (1993). Individual strategies for coping with stress at work: a review. Work \& Stress: An International Journal of Work, Health \& Organisations, 7(1), 5-15. doi: 10.1080/02678379308257046

Doef, M. van der, Maes, S., \& Diekstra, R. (2000). An examination of the job-demand-control-support model with occupational strain indicators. Anxiety, Stress \& Coping, 13(2), 165-185. doi: $10.1080 / 10615800008248338$

Fleck, M. P. A., Louzada, S., Xavier, M., Chachamovich, E., Vieira, G., Santos, L., \& Pinzon, V. (2000). Aplicação da versão em português do instrumento WHOQOL-Bref. Revista Saúde Pública, 34, 178-183. doi: 10.1590/S0034-89102000000200012

Folkman, S. (1984). Personal control and stress and coping processes: a theoretical analysis. Journal of Personality and Social Psychology, 46(4), 839-852. doi: 10.1037/0022-3514.46.4.839

Folkman, S., \& Lazarus, R. (1980). An analysis of coping in a middle-aged community sample. Journal of Health and Social Behavior, 21(3), 219-239.

França, A. (2007). Stress e trabalho: uma abordagem psicossomática. São Paulo: Atlas.

França, A. (2010). Qualidade de vida no trabalho-QVT: conceitos e prática nas empresas da sociedade pós-industrial. São Paulo: Atlas. 
Galanakis, M., Galanopoulou, F., \& Stalikas, A. (2011). Do positive emotions help us cope with occupational stress? Europe's Journal of Psychology, 7(2), 221-240.

Ganster, D. C. (2005). Executive job demands: suggestions from a stress and decision-making perspective. Academy of Management Review, 30(3), 492-502. doi: 10.5465/AMR.2005.17293366

Giga, S. I., Cooper, C. L., \& Faragher, B. (2003). The development of a framework for a comprehensive approach to stress management interventions at work. International Journal of Stress Management, 10(4), 280-296. doi: 10.1037/1072-5245.10.4.280

Greco, P., Magnago, T., Prochnow, A., Beck, C., \& Tavares, J. (2011). Utilização do modelo demandacontrole de Karasek na América Latina: uma pesquisa demográfica. Revista de Enfermagem da UFSM, 1(2), 272-281.

Griffith, J., Steptoe, A., \& Cropley, M. (1999). An investigation of coping strategies associated with job stress in teachers. British Journal of Health Psychology, 69(Pt 4), 517-531.

Häusser, J. A., Mojzisch, A., Niesel, M., \& Shulz-Hardt, S. (2010). Ten years on: a review of recent research on the job demand-control (-support) model and psychological well-being. Work \& Stress: An International Journal of Work, Health \& Organisations, 24(1), 1-35. doi: $10.1080 / 02678371003683747$

Haynes, N. S., \& Love, P. E. D. (2004). Psychological adjustment and coping among construction project managers. Construction Management \& Economics, 22(2), 129-140. doi: $10.1080 / 0144619042000201330$

Hu, H.-H. S., \& Cheng, C.-W (2010). Job stress, coping strategies, and burnout among hotel industry supervisors in Taiwan. The International Journal of Human Resource Management, 21(8), 13371350. doi: 10.1080/09585192.2010.483867

Johnson, J. V., Hall, E. M., \& Theorell, T. (1989). Combined effects of job strain and social isolation on cardiovascular disease morbidity and mortality in a random sample of the Swedish male working population. Scandinavian Journal of Work, Environment and Health, 15(4), 271-279.

Karasek, R. A., Jr. (1979). Job demand, job decision latitude, and mental strain: implications for job redesign. Administrative Science Quarterly, 24(2), 285-308. doi: 10.2307/2392498

Karasek, R. A., Jr., \& Theorell, T. (1990). Healthy work: stress, productivity and the reconstruction of working life. New York: Basic Books.

Karthik, R. (2013). A study on work-life balance in Chennai port trust, Chennai. Advances in Management, 6(7), 26-31.

Keith, K. D. (2001). International quality of life: current conceptual, measurement, and implementation issues. International Review of Research in Mental Retardation, 24, 49-74. doi: 10.1016/S00747750(01)80005-7

Kluthcovsky, A. C. G. C., \& Kluthcovsky, F. A. (2009). O WHOQOL-bref, um instrumento para avaliar qualidade de vida: uma revisão sistemática. Revista de Psiquiatria do Rio Grande do Sul, 31(3), 1-12. Recuperado de http://www.scielo.br/pdf/rprs/v31n3s0/v31n3a07s1.pdf. doi: 10.1590/S0101-81082009000400007

Kuchinke, K. P., Cornachione, E. B., Oh, S. Y., \& Kang, H-S. (2010). All work and no play? The meaning of work and work stress of mid-level managers in the United States, Brazil and Korea. Human Resource Development International, 13(4), 393-408. doi: $10.1080 / 13678868.2010 .501961$ 
Latack, J. C. (1986). Coping with job stress: measures and future directions for scale development. Journal of Applied Psychology, 71(3), 377-385. doi: 10.1037/0021-9010.71.3.377

Latack, J. C., \& Havlovic, S. J. (1992). Coping with job stress: a conceptual evaluation framework for coping measures. Journal of Organizational Behavior, 13(5), 479-508. doi: $10.1002 /$ job.4030130505

Lazarus, R., \& Folkman, S. (1984). Stress, appraisal and coping. New York: Sringer.

Lu, L., Kao, S.-F., Siu, O-L., S. \& Lu, C-Q. (2010). Work stressors, Chinese coping strategies, and job performance in greater China. International Journal of Psychology, 45(4), 294-302. doi: $10.1080 / 00207591003682027$

McClenahan, C. A., Giles, M. L., \& Mallett, J. (2007). The importance of context specificity in work stress research: a test of the demand-control-support model in academics. Work \& Stress: An International Journal of Work, Health \& Organisations, 21(1), 85-95. doi: $10.1080 / 02678370701264552$

Mukherjee, S. B., \& Ray, A. (2009). Innovative work behavior of managers: implications regarding stressful challenges of modernized public and private-sector organizations. Industrial Psychiatry Journal, 18(2), 101-107. doi: 10.4103/0972-6748.62269

Parris, M. A., Vickerss, M. H., \& Wikes, L. (2008). Caught in the middle: organizational impediments to middle manager's work-life balance. Employee Responsibilities and Rights Journal, 20(2), 101-117. doi: 10.1007/s10672-008-9069-z

Pelfrene, E., Vlerick P., Mak, R. P., De Smet, P., Kornitzer, M., \& De Backer, G. (2001). Scale reliability and validity of the Karasek job demand-control-support model in the belstress study. Work \& Stress: An International Journal of Work, Health \& Organisations, 15(4), 297-313. doi: $10.1080 / 02678370110086399$

Pinheiro, F. A., Tróccoli, B. T., \& Tamayo, M. R. (2003). Mensuração de coping no ambiente ocupacional. Psicologia: Teoria e Pesquisa, 19(2), 153-158. doi: 10.1590/S010237722003000200007

Richmond, A., \& Skitmore, M. (2006). Stress and coping: a study of project managers in large ICT organizations. Project Management Journal, 37(5), 5-16.

Saxena, S., Carlson, D., Billington, R., \& Orley, J. (2001). The WHO quality of life assessment instrument (WHOQOL-Bref): the importance of items for cross-cultural research. Quality of Life Research, 10(8), 711-721. doi: 10.1023/A:1013867826835

Shirrmeister, R., \& França A. (2012). A qualidade de vida no trabalho: relações com o comprometimento organizacional nas equipes multicontratuais. Revista Psicologia Organizações e Trabalho, 12(3), 283-298.

Stone, A. A., \& Neale, J. M. (1984). New measure of daily coping: development and preliminary results. Journal of Personality and Social Psychology, 46(4), 892-906. doi: 10.1037/0022-3514.46.4.892

Tulasi, V., \& Vijayalakshmi, C. (2013). Quality of work life: a strategy for good industrial relations. Advances in Management, 6(11), 8-15.

Weaver, R. (2010). Cost of presenteeism surpasses absenteeism. Recuperado de http://www.examiner.com/human-capital-in-detroit/cost-of-presenteeism-surpasses-absenteeism

Worral, L., \& Cooper, C. (2012). Quality of working life: managers wellbeing, motivation and productivity. London: Chartered Management Institute. 